\title{
Mixed Layer Temperature Response to the Southern Annular Mode: Mechanisms and Model Representation
}

\author{
James A. Screen, ${ }^{*}$ NAthan P. Gillett ${ }^{+}{ }^{+}$And Alexey Yu. KarpechKo \\ Climatic Research Unit, School of Environmental Sciences, University of East Anglia, Norwich, United Kingdom \\ DAVID P. STEVENS \\ School of Mathematics, University of East Anglia, Norwich, United Kingdom
}

(Manuscript received 11 December 2008, in final form 13 July 2009)

\begin{abstract}
Previous studies have shown that simulated sea surface temperature (SST) responses to the southern annular mode (SAM) in phase 3 of the Coupled Model Intercomparison Project (CMIP3) climate models compare poorly to the observed response. The reasons behind these model inaccuracies are explored. The ocean mixed layer heat budget is examined in four of the CMIP3 models and by using observationsreanalyses. The SST response to the SAM is predominantly driven by sensible and latent heat flux and Ekman heat transport anomalies. The radiative heat fluxes play a lesser but nonnegligible role. Errors in the simulated SST responses are traced back to deficiencies in the atmospheric response to the SAM. The models exaggerate the surface wind response to the SAM leading to large unrealistic Ekman transport anomalies. During the positive phase of the SAM, this results in excessive simulated cooling in the $40^{\circ}-65^{\circ} \mathrm{S}$ latitudes. Problems with the simulated wind stress responses, which relate partly to errors in the simulated winds themselves and partly to the transfer coefficients used in the models, are a key cause of the errors in the SST response. In the central Pacific sector $\left(90^{\circ}-150^{\circ} \mathrm{W}\right)$, errors arise because the simulated SAM is too zonally symmetric. Substantial errors in the net shortwave radiation are also found, resulting from a poor representation of the changes in cloud cover associated with the SAM. The problems in the simulated SST responses shown by this study are comparable to deficiencies previously identified in the CMIP3 multimodel mean. Therefore, it is likely that the deficiencies identified here are common to other climate models.
\end{abstract}

\section{Introduction}

Climate variability in the extratropical Southern Hemisphere is strongly influenced by variations in the southern annular mode (SAM). The SAM is the leading mode of extratropical atmospheric variability, explaining approximately $20 \%-30 \%$ of the total monthly sea level pressure (SLP) or geopotential height variability south of $20^{\circ} \mathrm{S}$ (Thompson and Wallace 2000; Thompson and Solomon

\footnotetext{
* Current affiliation: School of Earth Sciences, University of Melbourne, Melbourne, Victoria, Australia.

+ Current affiliation: Canadian Centre for Climate Modelling and Analysis, University of Victoria, Victoria, British Columbia, Canada.

Corresponding author address: James A. Screen, School of Earth Sciences, University of Melbourne, Melbourne, VIC 3010, Australia.

E-mail: screenj@unimelb.edu.au
}

2002; Hall and Visbeck 2002; Cai and Watterson 2002). The SAM is essentially a zonally symmetric barotopic mode with synchronous anomalies of opposite signs over Antarctica and the midlatitudes. The positive phase of the SAM is associated with negative SLP anomalies in the high latitudes, positive SLP anomalies in the midlatitudes, and strengthened circumpolar westerly winds. In the negative phase the anomalies are reversed.

The SAM is of particular interest because it has shown a trend toward its positive phase over recent decades (Thompson et al. 2000; Marshall et al. 2004; Marshall 2007). This trend is almost certainly human induced and is driven both by stratospheric ozone depletion and increased greenhouse gas concentrations (Gillett and Thompson 2003; Marshall et al. 2004; Shindell and Schmidt 2004; Arblaster and Meehl 2005; Miller et al. 2006; Cai and Cowan 2007). Climate models project a continued increase in the SAM index throughout the twenty-first century in line with projected increases in 
greenhouse gas emissions, although ozone stabilization and subsequent recovery may slow the rate of increase (Shindell and Schmidt 2004; Arblaster and Meehl 2005; Miller et al. 2006). Coupled climate-chemistry models, with an interactive chemistry component and an improved representation of the stratosphere, suggest a reversal of the SAM trend in the austral summer months resulting from expected ozone recovery (Perlwitz et al. 2008; Son et al. 2008). However, the time scale for ozone recovery is still uncertain (Eyring et al. 2007). Regardless of the direction of future trends, changes in the SAM are expected to play an important role in Southern Hemisphere climate over the coming decades. Understanding how these changes will affect future climate requires knowledge of how the SAM influences the climate system and an accurate representation of these processes in climate models.

Variations in the SAM have been shown to have a profound effect on many climate variables, including Antarctic temperatures (Gillett et al. 2006; Marshall 2007), precipitation (Gillett et al. 2006), ocean circulation (Hall and Visbeck 2002; Sen Gupta and England 2006), sea ice concentrations (Lefebvre et al. 2004; Stammerjohn et al. 2008), biological productivity (Lovenduski and Gruber 2005), and the carbon cycle (Butler et al. 2007; Lovenduski et al. 2007). Local surface forcing by the SAM has been shown to drive observed (Verdy et al. 2006; Ciasto and Thompson 2008) and simulated (Hall and Visbeck 2002; Sen Gupta and England 2006; Screen et al. 2009) sea surface temperature (SST) anomalies. These SST anomalies can feed back positively on the SAM (Watterson 2001; Sen Gupta and England 2007). SAM-induced SST anomalies have long persistence (Ciasto and Thompson 2008) and can influence the overlying atmosphere (Sen Gupta and England 2007), sea ice (Lefebvre et al. 2004), and marine ecosystems (Lovenduski and Gruber 2005).

Karpechko et al. (2009) tested the ability of the third phase of the Coupled Model Intercomparison Project (CMIP3) coupled climate models to simulate the observed surface air temperature (SAT) and SST responses to the SAM. These authors demonstrate that models are able to simulate the observed SAT response reasonably well, but the simulated SST responses are less realistic. The reasons behind these model inaccuracies remain poorly understood. The goal of this study is to provide a greater understanding of the discrepancies between the simulated and observed SST responses to the SAM. We present a detailed analysis of the dominant terms of the ocean mixed layer heat budget in a subset of the CMIP3 models and in observations/reanalyses.

Previous studies have considered the mechanisms driving the SST response to the SAM. Both Verdy et al.
(2006) and Ciasto and Thompson (2008) show good resemblance between the spatial pattern of the SST response and the spatial pattern of the combined response of the turbulent (sensible and latent) heat fluxes and the Ekman heat flux using reanalysis data. However, neither of the studies attempts to either close the mixed layer heat budget or compare the magnitudes of the SST and heat flux responses. Sen Gupta and England (2006) draw similar conclusions after examining the mixed layer heat budget in the National Center for Atmospheric Research (NCAR) Community Climate System Model, version 2 (CCSM2). However, these authors did not conduct a similar analysis with observed data and we can only speculate at the causes of error in the simulated SST response. For this reason, we revisit the mechanisms behind the SST response to the SAM and extend previous work by 1) examining the air-sea heat fluxes separately, 2) explicitly closing the mixed layer heat budget, and 3) comparing model output to observational and reanalysis datasets.

\section{Data and methods}

We used a subset of six simulations, from four different models (Table 1), included in the World Climate Research Program's CMIP3 dataset (see Meehl et al. 2007 for details) compiled in support of the Intergovernmental Panel on Climate Change (IPCC) Fourth Assessment Report (AR4; Solomon et al. 2007). We analyzed twentieth-century simulations (1900-99) of the third climate configuration of the Met Office Unified Model (HadCM3; runs 1 and 2), Goddard Institute for Space Studies Atmosphere-Ocean Model (GISS-AOM; runs 1 and 2), Centre National de Recherches Météorologiques Coupled Global Climate Model, version 3 (CNRM-CM3), and L'Institut Pierre-Simon Laplace Coupled Model, version 4 (IPSL CM4). This subset of models was selected solely due to data availability. Out of all the CMIP3 models, only CNRM-CM3, IPSL CM4, and GISS-AOM had all of the required model fields available. HadCM3 had all fields available except for mixed layer depth. Here we used HadCM3 mixed layer depth from a 100-yr section of a preindustrial control run.

Validation of climate model output is always difficult in the high southern latitudes because of a shortage of in situ data. To validate atmospheric parameters, we compared model output with reanalyses, following other model validation studies in the high southern latitudes (e.g., Connolley and Bracegirdle 2007; Karpechko et al. 2009). Atmospheric fields came from the 40-yr European Centre for Medium-Range Weather Forecasting (ECMWF) reanalysis (ERA-40; Uppala et al. 2005) and the National Centers for Environmental Prediction 
TABLE 1. Summary of the datasets. [Kraus-Turner bulk model: Kraus and Turner (1967), K-profile parameterization: Large et al. (1994), turbulent kinetic energy (TKE) scheme: Blanke and Delecluse (1993).]

\begin{tabular}{lcccc}
\hline \hline \multicolumn{1}{c}{ Dataset } & $\begin{array}{c}\text { Atmospheric resolution } \\
(\text { lat } \times \text { lon })\end{array}$ & $\begin{array}{c}\text { Oceanic resolution } \\
(\text { lat } \times \text { lon })\end{array}$ & $\begin{array}{c}\text { Ocean levels } \\
\text { (in top 100 m) }\end{array}$ & Mixed layer depth criterion \\
\hline HadCM3 & $2.50 \times 3.75^{\circ}$ & $1.25 \times 1.25^{\circ}$ & $20(7)$ & $\begin{array}{c}\text { Kraus-Turner bulk model } \\
\text { K-profile parameterization }\end{array}$ \\
GISS-AOM & $3.0 \times 4.0^{\circ}$ & $3.0 \times 4.0^{\circ}$ & $16(7)$ & $\Delta \rho_{z-0 \mathrm{~m}}>0.01 \mathrm{~kg} \mathrm{~m}{ }^{-3}$ \\
CNRM-CM3 & $2.8 \times 2.8^{\circ}$ & $1.0 \times 2.0^{\circ}$ & $31(10)$ & TKE scheme \\
IPSL CM4 & $2.50 \times 3.75^{\circ}$ & $1.0 \times 2.0^{\circ}$ & $31(10)$ & - \\
ERA-40 & $2.5 \times 2.5^{\circ}$ & - & - & - \\
NCEP-NCAR & $1.9 \times 1.9^{\circ}$ & - & 1 & - \\
HadISST & - & $1.0 \times 1.0^{\circ}$ & 1 & - \\
NOAA OI & - & - & 1 & - \\
ISCCP & $2.5 \times 2.5^{\circ}$ & $2.0 \times 2.0^{\circ}$ & & $\left|\Delta \mathrm{T}_{z-10 \mathrm{~m}}\right|>0.2 \mathrm{~K}$ \\
Mixed layer depth obs & - & &
\end{tabular}

(NCEP)-NCAR reanalysis (Kalnay et al. 1996). SST observations came from both the Hadley Centre Global Sea Ice and Sea Surface Temperature (HadISST; Rayner et al. 2003) and National Oceanic and Atmospheric Administration (NOAA) optimum interpolation (OI; Reynolds et al. 2002) datasets. Both SST products are derived from quality-controlled in situ measurements and satellite estimates (from 1982 onward) and are interpolated to monthly global fields on a $1^{\circ}$ latitudelongitude grid. While both SST products are based on essentially the same input data, the interpolation differs. Satellite estimates of cloud cover came from the International Satellite Cloud Climatology Project (ISCCP) D2 dataset (Rossow and Schiffer 1999) from July 1983 to June 2006. Observed mixed layer depth was taken from the de Boyer Montégut et al. (2004) climatology.

The reanalyses provide superior spatial and temporal coverage than in situ observations alone, but their quality is heavily dependent on the level of observational constraint. Some studies have identified problems with the reanalyses (Marshall 2003; Sterl 2004; Bromwich and Fogt 2004) and HadISST (Rayner et al. 2003) because of a lack of observational constraint prior to the assimilation of satellite data. Consequently, we limit our analyses to solely the modern satellite era; ERA-40 data were used for the period of 1979-2001 (this reanalysis project ended in 2001), NCEP-NCAR reanalysis data for 1979-2007, and both SST products over the period of 1982-2007. We have used multiple reference datasets to assess the impacts of biases in the reanalysis models. The differences between the reference datasets were small in comparison to the differences between the models, and to the differences between the models and the reference datasets. Our results were largely insensitive to the choice of reference dataset. Such similarity between reference datasets is reassuring but does not rule out common biases that may arise because the reanalyses have been made using largely the same observations, which them- selves contain errors (Bengtsson et al. 2004; Reichler and Kim 2008). Reichler and Kim (2008) show that observational uncertainties are generally smaller than the biases in the reanalysis models; however, in the cases of the air-sea fluxes (where relatively few direct observations exist) the observational uncertainties may exceed the errors in the reanalyses' global mean state. The extent to which these observational uncertainties affect the SAM responses in the reanalyses is unclear. What we can say is that, in our heat budget analysis, the residual components were no larger in the reanalyses than in the models, implying that observational biases in the surface heat fluxes do not undermine our key conclusions.

The SAM indices were derived by projecting monthly mean $500-\mathrm{hPa}$ geopotential height anomalies onto the leading empirical orthogonal function south of $20^{\circ} \mathrm{S}$. The $500-\mathrm{hPa}$ level was chosen rather than SLP to avoid the reduction of pressure to sea level over the high altitudes of Antarctica. SAM indices were defined separately for each simulation and for both reanalyses. The SAM indices from different models had differing variances. To account for this we normalized the NCEPNCAR reanalysis SAM index by its standard deviation and divided all other SAM indices by the standard deviation of the NCEP-NCAR index. Over the overlapping period (1979-2001) the ERA-40 and NCEPNCAR SAM indices have comparable standard deviations and are highly correlated (Pearson correlation $r=0.98$ ). Observed SST and cloud cover were regressed against the NCEP-NCAR SAM index because data were available to 2007.

Linear regression was used as a tool to study the effects of the SAM on numerous atmospheric and oceanic parameters. Where necessary, oceanic fields were linearly interpolated to the atmospheric grid. Before calculating the regression coefficients all of the time series were deseasonalized and linearly detrended. The statistical significance of the regression coefficients was calculated, 

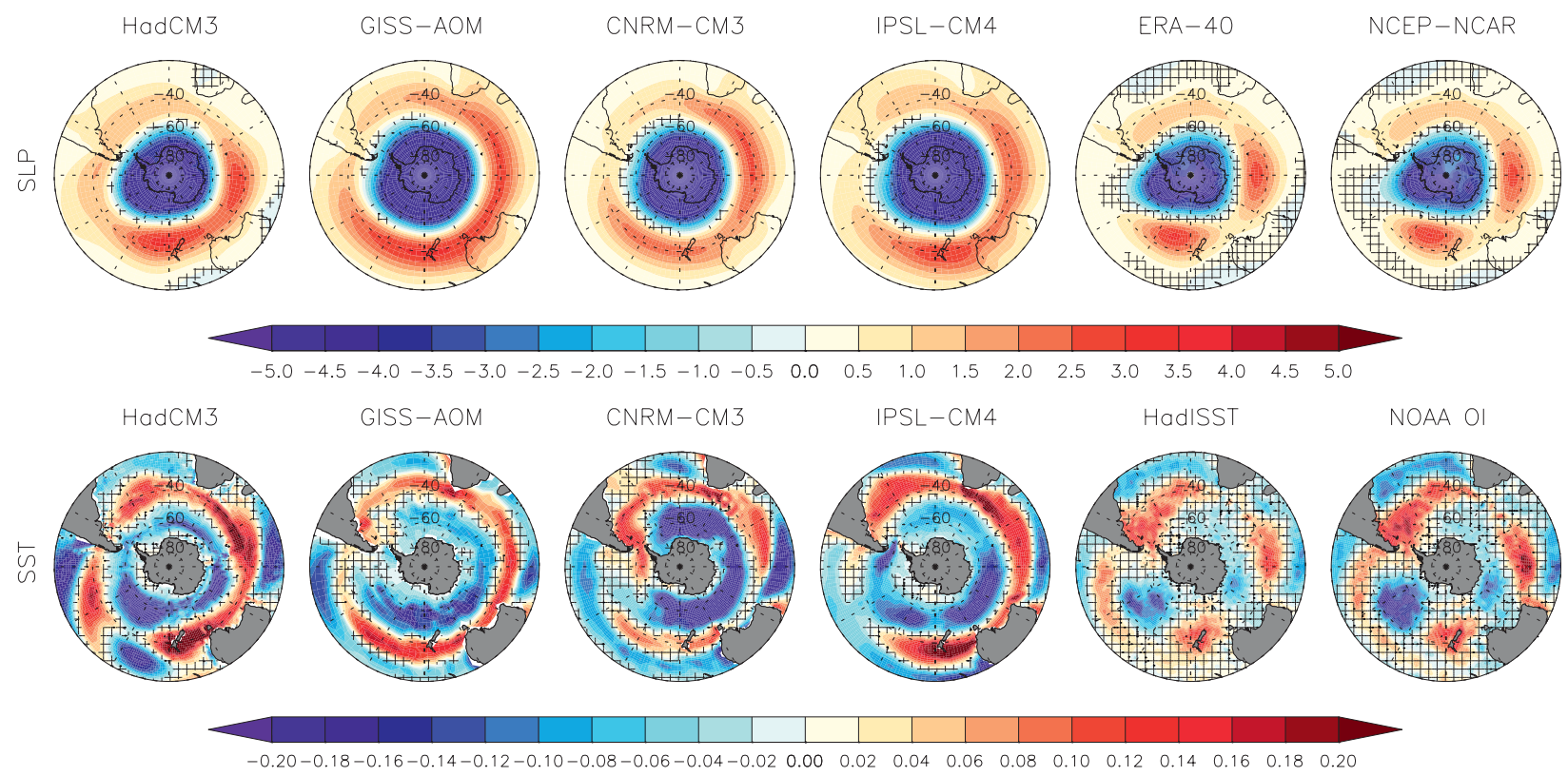

FIG. 1. Regression of monthly mean (top) sea level pressure (hPa) and (bottom) sea surface temperature $\left({ }^{\circ} \mathrm{C}\right)$ on the SAM index in (from left to right) HadCM3, GISS-AOM, CNRM-CM3, IPSL CM4, ERA-40 (HadISST), and NCEP-NCAR (NOAA OI). The crosshatching indicates regressions below the $95 \%$ significance level.

allowing for temporal autocorrelation, using a standard two-tailed $t$ test in which the effective sample size $N_{\text {eff }}$ was estimated as

$$
N_{\text {eff }}=N\left(\frac{1-r_{1} r_{2}}{1+r_{1} r_{2}}\right)
$$

where $N$ is the sample size and $r_{1}$ and $r_{2}$ are the lag-one autocorrelations of the two time series being regressed (Bretherton et al. 1999). Monthly means were used throughout. All regression maps correspond to a one unit positive anomaly in the SAM index. By definition, the anomalies are opposite in response to a one unit decrease in the SAM index.

The results from multiple runs of the same model (HadCM3 and GISS-AOM) were highly similar, revealing that intramodel differences in the SAM responses were small; they were negligible in comparison to the differences across models. Therefore, we have concatenated the simulations and SAM indices (after detrending and deseasonalizing) and present only one set of results for each model.

\section{Sea level pressure response}

As previously mentioned, the SAM is characterized by SLP anomalies of opposite signs over Antarctica and the midlatitudes. Figure 1 (top row) shows the SLP anomalies associated with the positive SAM phase. Al- though the SAM is largely zonally symmetric, the reanalyses display significant zonal asymmetry in the central Pacific sector $\left(90^{\circ}-150^{\circ} \mathrm{W}\right)$, as noted in previous studies (Thompson and Wallace 2000; Sen Gupta and England 2006; Gillett et al. 2006; Karpechko et al. 2009). The SLP responses in the reanalyses also display two centers of positive anomalies in the midlatitudes $\left(90^{\circ} \mathrm{E}\right.$ and $\left.170^{\circ} \mathrm{W}\right)$. The responses in the ERA-40 and NCEP-NCAR reanalyses are highly similar, suggesting strong observational constraint. Furthermore, the SLP response appears robust between the 1979-2001 and 1979-2007 periods.

All of the models capture the large-scale structure of the SLP response reasonably well. However, in comparison to the reanalyses, the simulated responses are too zonally symmetric. The asymmetry in the central Pacific is poorly represented. A similar result has been shown separately in other models (Sen Gupta and England 2006; Raphael and Holland 2006) and in the CMIP3 multimodel mean (Karpechko et al. 2009). The reanalyses have two distinct centers of positive SLP response in the midlatitudes, whereas the simulations display positive anomalies, of comparable magnitude to the reanalyses response centers, over a wider longitude range. In three of the four models (excluding HadCM3), the positive anomaly band is shifted north by approximately $5^{\circ}$ compared to the reanalyses and the negative anomaly band is expanded. We will show that these discrepancies propagate to other atmospheric fields and in turn to the mixed layer temperature response. 


\section{Sea surface temperature response}

The SST responses to a positive anomaly in the SAM indices are shown in Fig. 1 (bottom row). The observed responses display pronounced cooling in the central Pacific sector $\left(90^{\circ}-150^{\circ} \mathrm{W}\right)$ south of $40^{\circ} \mathrm{S}$, between $0^{\circ}$ and $130^{\circ} \mathrm{E}$ south of $50^{\circ} \mathrm{S}$ and in the Atlantic and Indian Oceans north of $30^{\circ} \mathrm{S}$. Warming is found across much of the Atlantic and Indian Oceans at latitudes of $30^{\circ}-45^{\circ} \mathrm{S}$, the ocean surrounding New Zealand, the eastern Pacific sector $\left(70^{\circ}-120^{\circ} \mathrm{W}\right)$ at latitudes of $25^{\circ}-35^{\circ} \mathrm{S}$ and in the Drake Passage-western Atlantic region. A similar SST response has been previously shown (Verdy et al. 2006; Sen Gupta and England 2006; Ciasto and Thompson 2008). The SST responses in HadISST and NOAA OI have highly similar spatial patterns, but the magnitude of the response is slightly greater in the latter. Karpechko et al. (2009) quantify this difference; the magnitude of the SST response is about $30 \%$ larger in NOAA OI. This can be explained by larger monthly variability in this dataset and ultimately stems from differences between the interpolation techniques used in the two SST datasets (Rayner et al. 2003).

The simulated SST responses display predominant cooling in the latitudes of $50^{\circ}-65^{\circ} \mathrm{S}$ and warming between $30^{\circ}$ and $45^{\circ} \mathrm{S}$ (Fig. 1, bottom row). In general, the simulations exaggerate the SST response and the response is too zonally symmetric in comparison to observations. The reasons behind these discrepancies are discussed later. CNRM-CM3 has a particularly poor representation of the observed SST response. This model fails to capture the cooling maximum in the central $\mathrm{Pa}$ cific, hugely overestimates the cooling at other longitudes, and displays cooling across the midlatitude Pacific in contrast to the observed warming response in this region. IPSL CM4 and GISS-AOM have more realistic magnitudes but are too zonally symmetric. HadCM3 has a more realistic spatial pattern but substantially overestimates the strength of the response. Similar deficiencies are shown quantitatively by Karpechko et al. (2009). These authors show that CNRM-CM3 ranks lowest of all the CMIP3 models in terms of its ability to capture the observed SST response to the SAM. IPSL CM4 also performs relatively poorly in their assessment. GISSAOM and HadCM3 rank in the middle of the CMIP3 models. Subsampling all of the simulations over periods equal in length to the observations produces comparable robust regression patterns (not shown).

\section{Mixed layer heat budget}

SST anomalies are the surface expression of changes in heat content throughout the mixed layer. The mixed layer heat content is dependent on air-sea heat fluxes and heat advection by ocean currents and small-scale mixing. We consider the mixed layer heat budget in which the mixed layer temperature tendency is given by

$$
\begin{aligned}
\frac{\partial T}{\partial t}= & \frac{Q_{\mathrm{SW}}+Q_{\mathrm{LW}}+Q_{L}+Q_{S}}{\rho c_{p} D}-\frac{u}{a \cos \phi} \frac{\partial T}{\partial \lambda}-\frac{v}{a} \frac{\partial T}{\partial \phi} \\
& -w \frac{\partial T}{\partial z}+\text { mixing, }
\end{aligned}
$$

where $T$ is the temperature; $Q_{\mathrm{Sw}}$ is the net shortwave radiation; $Q_{\mathrm{LW}}$ is the net longwave radiation; $Q_{L}$ is the latent heat flux; $Q_{S}$ is the sensible heat flux; $\rho$ is density; $c_{p}$ is the specific heat of seawater; $D$ is the mixed layer depth; $u, v$, and $w$ are the eastward, northward, and vertical components of ocean velocity; $\lambda, \phi$, and $z$ are the longitude, latitude, and depth; $t$ is time; and $a$ is the radius of the earth. The heat fluxes are divided by $D$ as they act on the entire mixed layer rather than at the surface alone.

Previous studies have shown that the budget is dominated by the air-sea heat fluxes and the horizontal advection terms, while the others terms make smaller contributions (Maze et al. 2006; Sen Gupta and England 2006). Accordingly, we neglect the effects of vertical advection and mixing. Furthermore, the near-surface velocity response to the SAM is dominated by winddriven Ekman transport anomalies (Sen Gupta and England 2006). This means the horizontal advective terms can be estimated directly from wind field through

$$
\begin{aligned}
-\frac{u}{a \cos \phi} \frac{\partial T}{\partial \lambda}-\frac{v}{a} \frac{\partial T}{\partial \phi} & \simeq \frac{1}{\rho f D}\left(-\frac{\tau^{y}}{a \cos \phi} \frac{\partial T}{\partial \lambda}+\frac{\tau^{x}}{a} \frac{\partial T}{\partial \phi}\right) \\
& =\frac{F_{\mathrm{EK}}}{\rho c_{p} D},
\end{aligned}
$$

where $f$ is the Coriolis parameter, $\tau^{x}$ and $\tau^{y}$ are the eastward and northward components of the surface wind stress, and $F_{\mathrm{EK}}$ is the Ekman heat convergence (Ekman 1905). Observed in situ near-surface transports are close to those predicted by Ekman theory (Chereskin and Roemmich 1991; Chereskin 1995; Schudlich and Price 1998). Equation (3) gives the convergence-divergence of heat resulting from Ekman transport. Because $F_{\mathrm{EK}}$ represents the heat transport resulting from the mean velocity in the Ekman layer, it is expressed as a heat flux per unit surface area (as supposed to per unit cross section). The Ekman layer depth is assumed to be less than or equal to the mixed layer depth. This is generally thought to be valid, although in certain locations Ekman transport penetrates below the mixed layer (Chereskin and Roemmich 1991; Chereskin and Price 2001). Based on this assumption, the horizontal temperature gradients 


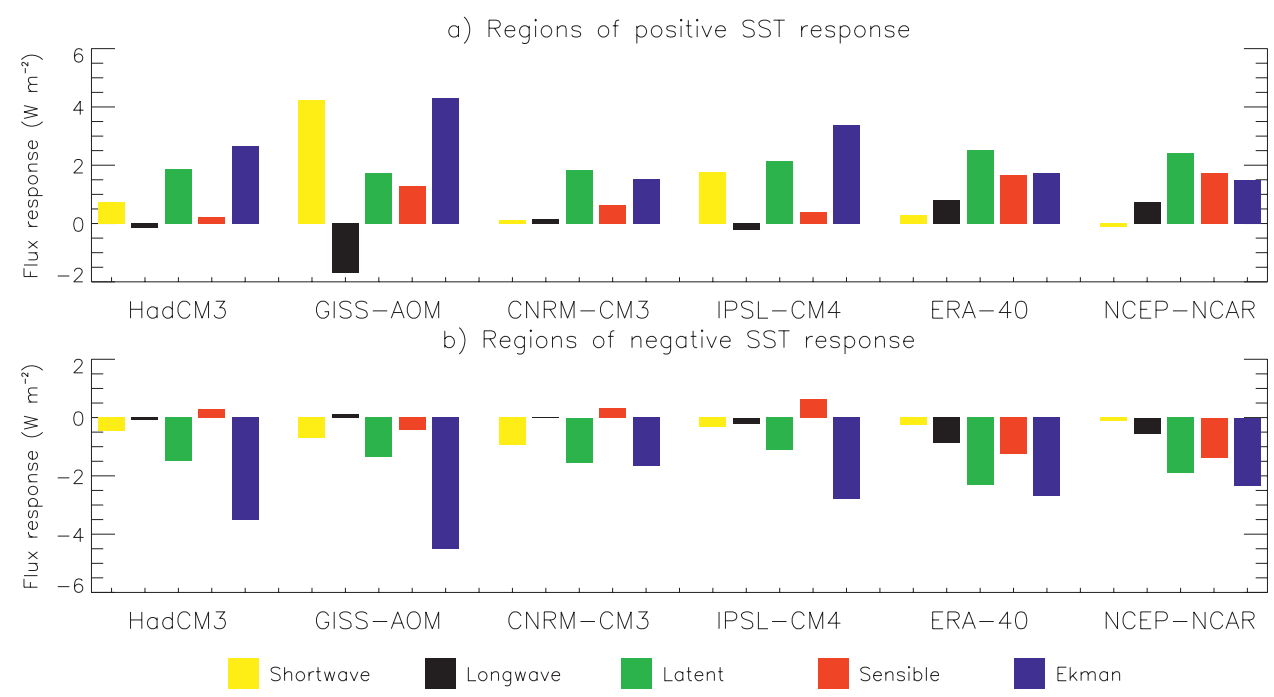

FIG. 2. Area-averaged regressions of the component terms of the mixed layer heat budget $\left(\mathrm{W} \mathrm{m}^{-2}\right)$ on the SAM index. Regressions have been averaged over regions corresponding to (a) positive SST response to the SAM and (b) negative SST response to the SAM [defined by SST-SAM regressions of (a) $\geq 0.05^{\circ} \mathrm{C}$ and (b) $\leq-0.05^{\circ} \mathrm{C}$ per 1 standard deviation increase in the SAM index, in each respective dataset].

are vertically constant, so the SST gradient is representative of the temperature gradient throughout the Ekman layer and all the Ekman heat transport occurs within the mixed layer.

Combining Eqs. (2) and (3) gives a simplified mixed layer heat budget:

$$
\frac{\partial T}{\partial t}=\frac{Q_{\mathrm{SW}}+Q_{\mathrm{LW}}+Q_{L}+Q_{S}+F_{\mathrm{EK}}}{\rho c_{p} D} .
$$

Figure 2 shows the responses of the component terms of this simplified heat budget to a one standard deviation increase in the SAM index. In all cases, the air-sea fluxes are considered positive in the downward direction (i.e., into the ocean). Here we show the area-averaged response separately for the regions of positive SST response and for the regions of negative SST response (from Fig. 1, bottom row). Note that these regions were defined separately for each dataset. Thus, Fig. 2 shows the magnitudes and relative importance of the component heat budget terms to the specific SST response in each dataset. The spatial patterns of the responses, and the differences in these patterns between the simulations and reanalyses, are considered later.

In the reanalyses, the $Q_{L}$ term provides the largest contribution to the SST warming response (Fig. 2a). A one standard deviation increase in the SAM index is associated with an area-averaged increase in $Q_{L}$ of approximately $2.5 \mathrm{~W} \mathrm{~m}^{-2}$. The $Q_{S}$ and $F_{\mathrm{EK}}$ terms make comparable contributions of approximately $1.5 \mathrm{~W} \mathrm{~m}^{-2}$ in both ERA-40 and the NCEP-NCAR reanalysis. The radiative heat fluxes play a lesser role with area-averaged responses of less than $1 \mathrm{~W} \mathrm{~m}^{-2}$. The simulations show rather different contributions of the component heat budget terms. Three of four models (excluding CNRMCM3) exaggerate the $F_{\mathrm{EK}}$ contribution to the warming SST response. The same three models have overly strong $Q_{\text {Sw }}$ responses. For example, GISS-AOM displays areaaveraged $Q_{\mathrm{SW}}$ and $F_{\mathrm{EK}}$ responses of over $4 \mathrm{~W} \mathrm{~m}^{-2}$. In general, the simulations underestimate the $Q_{S}$ response in comparison to the reanalyses. The simulated $Q_{L}$ responses are of a reasonably realistic magnitude.

Turning to the regions of negative SST response (Fig. 2b), the $F_{\mathrm{EK}}$ term provides the largest contribution across all simulations and in the reanalyses. However, three of four models exaggerate the $F_{\mathrm{EK}}$ response. In particular, GISS-AOM displays an area-averaged $F_{\mathrm{EK}}$ response of $-4.5 \mathrm{~W} \mathrm{~m}^{-2}$, which is approximately twice the magnitude of the response in either ERA-40 or the NCEP-NCAR reanalysis. The $Q_{L}$ term is the second largest component to the SST cooling response in both the simulations and reanalyses (between -1 and $-2.5 \mathrm{~W} \mathrm{~m}^{-2}$ ). In the reanalyses, the $Q_{S}$ term contributes to cooling with an area-averaged response of approximately $-1.5 \mathrm{~W} \mathrm{~m}^{-2}$. The simulations underestimate the $Q_{S}$ response and three of the four models (excluding CNRM-CM3) display responses of an opposite sign to those of the reanalyses. The radiative heat fluxes play a minor role in the cooling response in both the reanalyses and the simulations.

Figure 2 hints at heat flux differences between the simulations and the reanalyses that may help explain the 

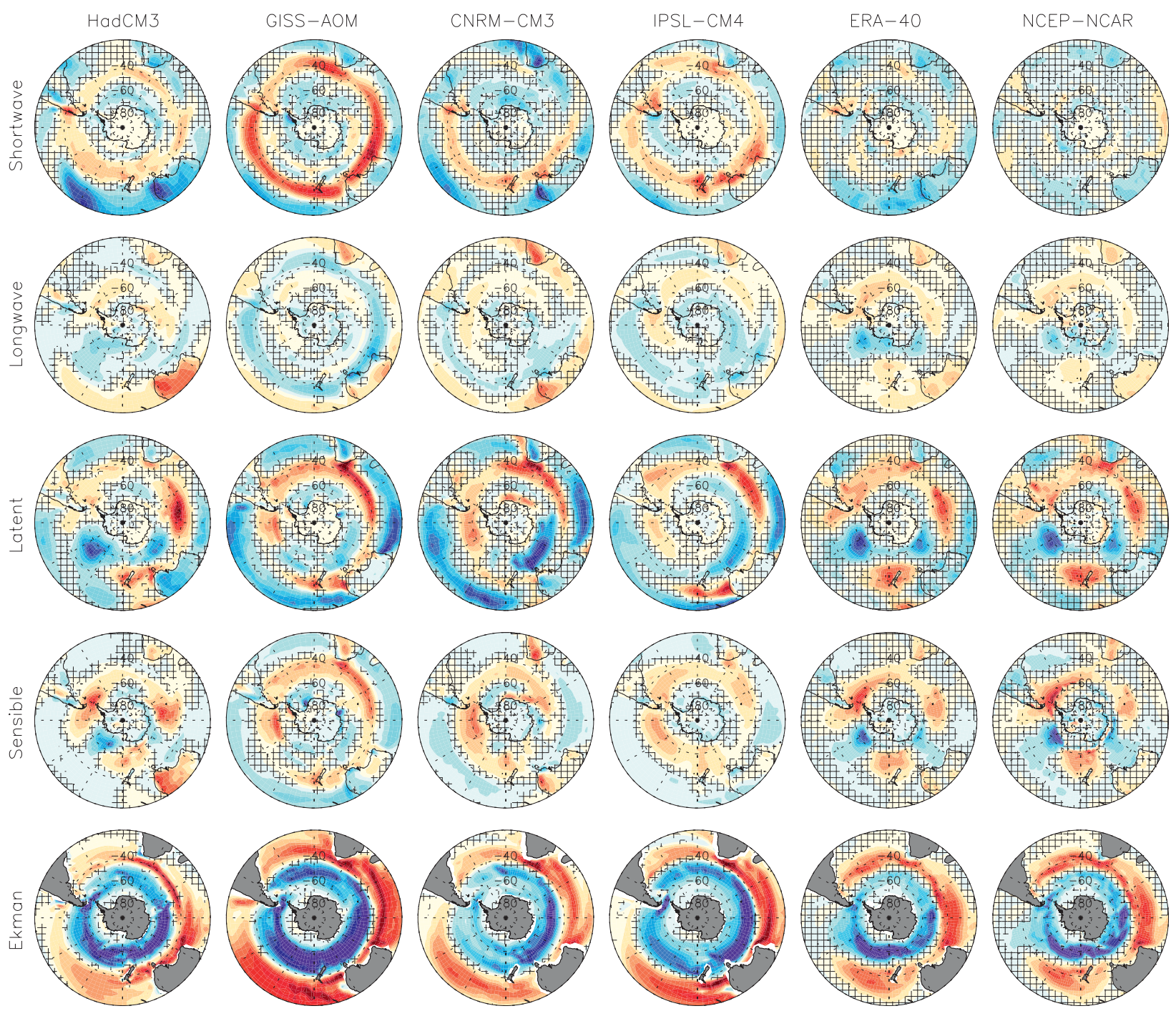

$\begin{array}{lllllllllllllllllllll}-10 & -9 & -8 & -7 & -6 & -5 & -4 & -3 & -2 & -1 & 0 & 1 & 2 & 3 & 4 & 5 & 6 & 7 & 8 & 9 & 10\end{array}$

FIG. 3. (top to bottom) Regressions of monthly mean net shortwave radiation, net longwave radiation, latent heat flux, sensible heat flux, and Ekman heat flux $\left(\mathrm{W} \mathrm{m}^{-2}\right.$ ) on to the SAM index in (from left to right) HadCM3, GISS-AOM, CNRM-CM3, IPSL CM4, ERA-40, and NCEP-NCAR. The cross-hatching indicates regressions below the $95 \%$ significance level. The ERA-40 Ekman heat flux was calculated using SST from HadISST and the NCEP-NCAR Ekman heat flux was calculated using SST from NOAA OI.

differences between the simulated and observed SST responses (Fig. 1, bottom row). To examine these discrepancies in more detail, the following sections individually address the SAM responses of the constituent terms of our simplified heat budget. For completeness, we plot the heat fluxes over land and ocean; however, the discussion focuses on the ocean regions.

\section{a. Shortwave radiation}

The simulated $Q_{\text {sw }}$ responses to the SAM show three approximately zonal bands of anomalies (Fig. 3, top row). There are negative $Q_{\mathrm{sw}}$ anomalies south of $\sim 50^{\circ} \mathrm{S}$ and north of $\sim 30^{\circ} \mathrm{S}$ and positive anomalies in the latitudes of $30^{\circ}-50^{\circ} \mathrm{S}$. The $Q_{\text {sw }}$ anomalies are likely to be associated with changes in cloud cover. Between $30^{\circ}$ and $50^{\circ} \mathrm{S}$, the SLP anomalies associated with positive SAM are positive (Fig. 1, top row), synonymous with descending air and decreased cloudiness. Reduced cloud cover in the latitudes of $30^{\circ}-50^{\circ} \mathrm{S}$ may also be related to a southward shift in the storm track during the positive phase of the SAM. The simulated regressions of total cloud cover on the SAM index (Table 2) show strong correspondence to the $Q_{\mathrm{SW}}$ responses; enhanced cloud cover in the $10^{\circ}-30^{\circ} \mathrm{S}$ latitude band is associated with 
TABLE 2. Area-averaged regression of net shortwave radiation $\left(\mathrm{W} \mathrm{m} \mathrm{m}^{-2}\right.$ ), net longwave radiation $\left(\mathrm{W} \mathrm{m}^{-2}\right)$, and total cloud cover $(\%)$ on the SAM index.

\begin{tabular}{lcccccccc}
\hline & \multicolumn{3}{c}{$10-30^{\circ} \mathrm{S}$} & & \multicolumn{3}{c}{$30-50^{\circ} \mathrm{S}$} \\
\cline { 2 - 5 } \cline { 7 - 9 } \multicolumn{1}{c}{ Dataset } & $Q_{\text {SW }}$ & $Q_{\text {LW }}$ & TCC & & $Q_{\text {SW }}$ & $Q_{\text {LW }}$ & TCC \\
\hline HadCM3 & -1.33 & 0.51 & 0.54 & & 0.44 & -0.03 & -0.56 \\
GISS-AOM & -1.14 & 0.76 & 1.20 & & 2.36 & -0.90 & -1.62 \\
CNRM-CM3 & -1.49 & 0.86 & 0.77 & & 0.65 & -0.29 & -0.59 \\
IPSL CM4 & -0.88 & 0.52 & 0.17 & & 1.56 & -0.33 & -0.58 \\
ERA-40 & -0.77 & 0.27 & 0.40 & & -0.07 & 0.47 & 0.28 \\
NCEP-NCAR & -0.12 & 0.10 & - & & -0.31 & 0.38 & - \\
ISCCP & - & - & 0.22 & & - & - & 0.21
\end{tabular}

negative $Q_{\mathrm{SW}}$ anomalies and decreased cloudiness in the $30^{\circ}-50^{\circ} \mathrm{S}$ band is collocated with positive $Q_{\text {sw }}$ anomalies. GISS-AOM has particularly strong $Q_{\text {Sw }}$ increases in the latitudes of $30^{\circ}-50^{\circ} \mathrm{S}$ associated with comparatively large decreases in cloud cover. The simulated $Q_{\text {Sw }}$ anomalies are strongly related to changes in cloud cover.

The reanalyses' $Q_{\text {Sw }}$ responses to the SAM are weaker and less symmetrical than the simulated responses (Fig. 3, top row). In particular, the positive response centered at $\sim 40^{\circ} \mathrm{S}$ is substantially weaker or nonexistent. Indeed, when averaging over the latitude band of $30^{\circ}-50^{\circ} \mathrm{S}$ the reanalyses show weak negative $Q_{\text {Sw }}$ responses (Table 2). All of the models overestimate the $Q_{\text {sw }}$ response. The largest discrepancies are found in GISS-AOM, which has overly strong increases over the latitudes of $30^{\circ}-45^{\circ} \mathrm{S}$ (Fig. 3, top row). There are pronounced differences between the total cloud cover responses in ERA-40 and ISCCP when compared to the simulations that in part explain the differing $Q_{\mathrm{SW}}$ responses (Table 2; note total cloud cover is not available from the NCEP-NCAR reanalysis). For instance, while the simulations show substantial decreases in cloud cover over the latitudes of $30^{\circ}-50^{\circ} \mathrm{S}$, both ERA-40 and ISCCP show weak increases in cloudiness. Subsequently, the simulations show comparatively strong $Q_{\text {SW }}$ increases over these latitudes in contrast to weak decreases in ERA-40 and NCEPNCAR reanalysis. The relationship between SLP and cloudiness appears weaker in ERA-40 than in the simulations; there is no area-mean decrease in cloud cover in the region of positive SLP response and descending air $\left(30^{\circ}-50^{\circ} \mathrm{S}\right)$. This feature of the simulated cloud response is also absent in ISCCP.

\section{b. Longwave radiation}

The reanalyses' $Q_{\mathrm{LW}}$ responses display positive anomalies over the ocean surrounding New Zealand and between $90^{\circ} \mathrm{W}-100^{\circ} \mathrm{E}$ at latitudes of $40^{\circ}-60^{\circ} \mathrm{S}$ (Fig. 3, second row). Negative $Q_{\mathrm{LW}}$ anomalies are seen in the reanalyses in the central Pacific sector, Ross Sea, and off the coast of Adélie Land $\left(90^{\circ}-170^{\circ} \mathrm{E}\right)$. The simulated
$Q_{\mathrm{LW}}$ responses differ considerably from the reanalyses. HadCM3 has the most realistic $Q_{\mathrm{LW}}$ response. The response in GISS-AOM is highly symmetric and closely related to the cloud response; regions with positive $Q_{\mathrm{LW}}$ response correspond to regions with enhanced cloudiness and vice versa (Table 2). CNRM-CM3 and IPSLCM4 both have unrealistic $Q_{\mathrm{LW}}$ anomaly patterns, in part associated with discrepancies in the cloud response.

\section{c. Latent heat flux}

The reanalyses's $Q_{L}$ responses are in close agreement with each other (Fig. 3, third row) and are noticeably larger than either the $Q_{\mathrm{Sw}}$ or $Q_{\mathrm{LW}}$ responses. During positive SAM, there is enhanced $Q_{L}$ stretching eastward from South America to Australia across the Atlantic and Indian sectors $\left(90^{\circ} \mathrm{W}-110^{\circ} \mathrm{E}, 35^{\circ}-55^{\circ} \mathrm{S}\right)$ and over the ocean surrounding New Zealand. Anomalies of the opposite sign are found in the central Pacific sector $\left(90^{\circ}-150^{\circ} \mathrm{W}, 40^{\circ}-65^{\circ} \mathrm{S}\right)$ and off the Adélie Land coast of Antarctica $\left(100^{\circ}-150^{\circ} \mathrm{E}, 45^{\circ}-65^{\circ} \mathrm{S}\right)$.

The simulated $Q_{L}$ responses are of reasonably realistic magnitude, but the spatial patterns are less realistic (Fig. 3, third row). Only HadCM3 successfully captures the negative $Q_{L}$ response in the central Pacific sector. The other models show a positive response in this region. This discrepancy appears related to problems with the simulated humidity anomalies associated with the SAM (not shown). The reanalyses display reduced humidity in the central Pacific in the positive phase of the SAM, which is not simulated by the models (excluding HadCM3). The positive $Q_{L}$ response surrounding New Zealand is poorly represented in CNRM-CM3 and IPSL CM4. Three out of four models (GISS-AOM, CNRM-CM3, and IPSL CM4) show significant decreases in $Q_{L}$ over the latitudes of $20^{\circ}-40^{\circ} \mathrm{S}$ that are not apparent in the reanalyses. The positive $Q_{L}$ response between $90^{\circ} \mathrm{W}-110^{\circ} \mathrm{E}$ at latitudes of $35^{\circ}-55^{\circ} \mathrm{S}$ is to some extent captured by all of the simulations, as is the negative response off the coast of Adélie Land $\left(100^{\circ}-150^{\circ} \mathrm{E}\right)$, although the response in CNRM-CM3 is overly strong here. The $Q_{L}$ anomalies are likely driven by changes in surface humidity. For those models in which relative humidity was an available output (HadCM3, CNRM$\mathrm{CM} 3$, and IPSL CM4), and in the reanalyses, the spatial patterns of $Q_{L}$ response resemble the spatial patterns of the humidity response, particularly over the ocean (not shown). Sen Gupta and England (2006) also find a close relationship between the $Q_{L}$ and surface humidity responses to the SAM in NCAR CCSM2.

\section{d. Sensible heat flux}

The reanalyses's $Q_{S}$ responses (Fig. 3, fourth row) are mainly confined to the latitudes of $40^{\circ}-65^{\circ} \mathrm{S}\left(Q_{S}\right.$ is small 
farther south because of the presence of sea ice). The largest $Q_{S}$ anomalies are found in the Drake Passagewestern Atlantic region where positive SAM is associated with enhanced $Q_{S}$ and in the central Pacific sector where $Q_{S}$ is reduced. Weaker centers of a positive $Q_{S}$ response are found at $75^{\circ}$ and $180^{\circ} \mathrm{E}$ and negative $Q_{S}$ response at $120^{\circ} \mathrm{W}$. The $Q_{S}$ responses show reasonable similarity to the SAT responses over ocean (not shown). This indicates that the dominant influence is from the atmosphere to the ocean, not the other way round. If the opposite case (from the ocean to the atmosphere) dominated, then the $Q_{S}$ response would resemble the SST response but with anomalies of the opposite sign (the flux is considered positive in the downward direction). This is clearly not the case here (cf. Fig. 1, bottom row and Fig. 3, fourth row). However, with lag of a few months, the SAM-induced SST anomalies, which have greater persistence than the atmospheric anomalies (Sen Gupta and England 2006; Ciasto and Thompson 2008), may influence the overlying atmosphere, albeit primarily through a reversal of the $Q_{L}$ response (Sen Gupta and England 2006). The warming response (and hence positive $Q_{S}$ response) in the Drake Passagewestern Atlantic and the cooling response (negative $Q_{S}$ response) in the central Pacific likely arise because of the asymmetry in the reanalyses's SLP responses (Fig. 1, top row). Because of this asymmetry, the geostrophic wind has a larger northward component and advects relatively cold air into the central Pacific region. Conversely, more southward wind advects relatively warm air in the Drake Passage-western Atlantic region. The two weaker centers of positive $Q_{S}$ response are also collocated with regions of southward advection by the geostrophic wind (Fig. 1, top row).

The models vary considerably in their $Q_{S}$ responses (Fig. 3, fourth row). HadCM3 has a fairly realistic $Q_{S}$ response and captures the main features seen in the reanalyses. In contrast, the other models have a more unrealistic $Q_{S}$ response. GISS-AOM, CNRM-CM3, and IPSL CM4 show very weak increases of $Q_{S}$ in the Drake Passage-western Atlantic region. In addition, none of these models capture the negative $Q_{S}$ response in the central Pacific seen in the reanalyses. Some of the discrepancies in the simulated $Q_{S}$ responses arise because of problems in the SAT responses (not shown). Compared to the reanalyses, the simulations show weaker or no warming in the Drake Passage-western Atlantic region. Similarly, only HadCM3 displays cooling in the central Pacific sector, as seen in the reanalyses. These differences between the simulated and reanalyses's SAT responses are likely related to the too zonally symmetric SLP (and therefore wind) responses in the models (Fig. 1, top row).

\section{e. Ekman heat transport}

Figure 3 (bottom row) shows the $F_{\mathrm{EK}}$ response to a one unit positive increase in the SAM. Time-varying SST gradients from HadISST and NOAA OI were used to derive $F_{\mathrm{EK}}$ for ERA-40 and the NCEP-NCAR reanalysis, respectively [refer to Eq. (3)]. The resulting $F_{\mathrm{EK}}$ responses are highly similar and insensitive to the choice of SST gradients from either NOAA OI or HadISST and wind stresses from either ERA-40 or the NCEP-NCAR reanalysis. All of the simulations and the reanalyses show an approximately zonally symmetric $F_{\mathrm{EK}}$ response, with negative anomalies in the latitudes of $45^{\circ}-65^{\circ} \mathrm{S}$ and positive anomalies between $20^{\circ}$ and $40^{\circ} \mathrm{S}$. By definition this pattern is wind driven and is dominated by the Ekman transport response to zonal wind stress anomalies associated with the SAM. Eastward wind stress anomalies in the latitudes of $45^{\circ}-65^{\circ} \mathrm{S}$ cause an equatorward transport of relatively cold water leading to negative $F_{\text {EK }}$ anomalies at these latitudes. Conversely, westward wind stress anomalies in the latitudes of $20^{\circ}-40^{\circ} \mathrm{S}$ result in a poleward transport of relatively warm water leading to positive $F_{\mathrm{EK}}$ anomalies in this latitude band.

In the reanalyses, the negative $F_{\mathrm{EK}}$ response extends farther northward in the central Pacific sector and breaks the ring of positive $F_{\mathrm{EK}}$ response in the midlatitudes (Fig. 3, bottom row). By comparison, the simulated responses are too zonally symmetric. This reflects the asymmetry in the reanalyses's SLP responses (Fig. 1, top row). This discrepancy between the reanalyses and simulations propagates to the wind stress responses and, in turn, the $F_{\mathrm{EK}}$ responses. There are also clear differences in the magnitude of the $F_{\mathrm{EK}}$ response, both between individual models and between the simulations and the reanalyses (Fig. 3, bottom row). Unsurprisingly, the magnitude of the $F_{\mathrm{EK}}$ response is highly dependent on the strength of the wind response to the SAM. GISSAOM shows the strongest wind stress response (Fig. 4) and $F_{\text {EK }}$ response (Fig. 3, bottom row). The wind stress response is weakest in ERA-40 (Fig. 4). All of the simulations exaggerate the wind stress response in comparison to the reanalyses.

The discrepancies in the wind responses can be partly explained by differences in the spatial patterns of the SLP responses (Fig. 1, top row). Although the most pronounced differences in the SLP responses, between the reanalyses and simulations, are found in the central Pacific sector $\left(90^{\circ}-150^{\circ} \mathrm{W}\right)$, there are differences elsewhere that also effect the wind response (similar deficiencies in the simulated wind responses to those shown in Fig. 4 are found if the central Pacific sector is excluded from the area average). In the simulations, the midlatitude positive SLP anomalies are comparatively 


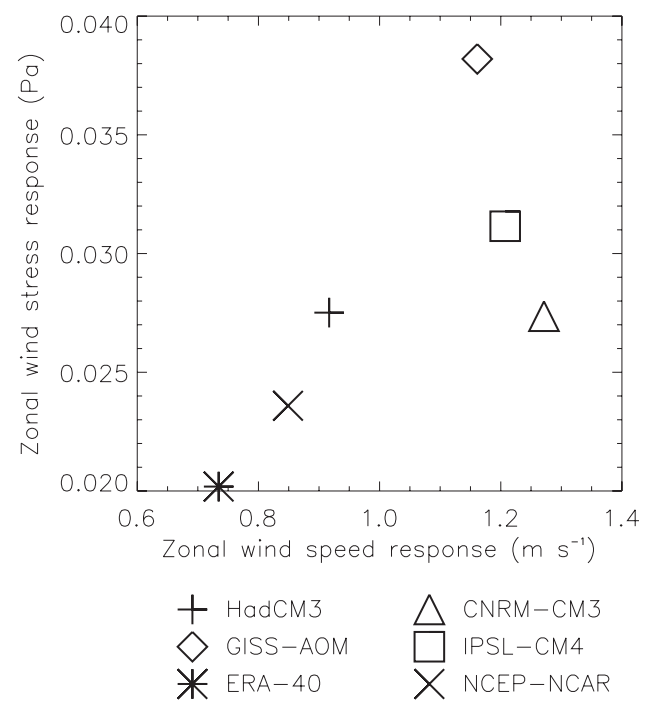

FIG. 4. Area-averaged $\left(45^{\circ}-65^{\circ} \mathrm{S}\right)$ regression of zonal surface wind speed $\left(\mathrm{m} \mathrm{s}^{-1}\right)$ on the SAM index plotted versus the regression of zonal surface wind stress $(\mathrm{Pa})$ on the SAM index.

large over a wider longitude range than in the reanalyses (Fig. 1, top row). Thus, at many longitudes, the meridional gradient of the SLP response is exaggerated in the simulations. Therefore, the wind response, which is largely geostrophic (Sen Gupta and England 2006), is also larger in the simulations than the reanalyses (Fig. 4). Comparing Fig. 1 (top row) and Fig. 3 (bottom row), it can be seen that the $F_{\text {EK }}$ response is enhanced in regions with a larger meridional gradient of SLP response.

It is interesting to note that the simulations with the largest surface wind speed responses to the SAM (CNRMCM3 and IPSL CM4) do not have the largest surface wind stress responses (Fig. 4). This is somewhat surprising because the wind stress is related to the square of the wind speed. Estimates of the wind stress $(\tau)$ typically take the form

$$
\boldsymbol{\tau}=\rho_{a} C_{D}|\mathbf{u}| \mathbf{u}
$$

where $\mathbf{u}$ is the wind speed, $C_{D}$ is a drag coefficient, and $\rho_{a}$ is the air density; $C_{D}$ is dependent on atmospheric stability and the wind speed but many different formulations exist (Josey et al. 2002). There is still uncertainty as to the formulation of $C_{D}$ that best represents reality, and models do not necessarily use the most sophisticated definition (Josey et al. 2002; Fairall et al. 2003). Different models use varying formulations for calculating the surface wind stresses. The results here suggest that the wind stress and $F_{\mathrm{EK}}$ responses to the SAM are sensitive to the formulation of the drag coefficients.

\section{f. Mixed layer temperature tendency}

Having examined the constituent terms separately, we now test whether the simplified heat budget can capture the SST response to the SAM. Equation 4 was used to estimate mixed layer temperature tendencies from the heat budget. To compare the heat budget and SST responses to the SAM, actual SST tendencies were calculated using the centered finite difference,

$$
\left(\frac{\partial \mathrm{SST}}{\partial t}\right)^{n}=\frac{\mathrm{SST}^{n+1}-\mathrm{SST}^{n-1}}{2 \Delta t}
$$

where $n$ denotes a particular month and $\Delta t=1$ month is the time step. The SST tendency will have contributions from the net fluxes in $n-1$ and $n+1$. Therefore, the mixed layer temperature tendencies calculated from the heat budget were replaced with the average

$$
\frac{1}{4}\left(\frac{\partial T}{\partial t}\right)^{n+1}+\frac{1}{2}\left(\frac{\partial T}{\partial t}\right)^{n}+\frac{1}{4}\left(\frac{\partial T}{\partial t}\right)^{n-1} .
$$

This estimates the mixed layer temperature tendencies over the same period as the SST tendencies. Recall that because of data constraints we assume that the mixed layer is homogeneous and that the SST is equal to the mixed layer temperature.

Figure 5 compares the SST tendency response to the SAM (top row) with the mixed layer temperature tendency response derived from the simplified heat budget (middle row). In all cases, there is good agreement between both the spatial patterns and magnitudes of the SST tendency responses to the SAM and the mixed layer tendency responses from the heat budget analysis. The main features of the SST tendency response are captured by the heat budget, suggesting that the dominant terms of the heat budget are the net air-sea heat flux and the Ekman heat flux, in agreement with earlier studies (Verdy et al. 2006; Sen Gupta and England 2006; Ciasto and Thompson 2008). The residual component (i.e., that not captured by the simplified heat budget) is shown in the bottom row. The residual components bear little resemblance to the SST tendency responses, suggesting that our simplified heat budget has captured a significant proportion of processes driving the SST tendency response. However, it is clear that the heat budget fails to capture some of the regional detail in the SST tendency response.

The presence of a residual component is not unsurprising because we have had to tailor the heat budget to suit the available observations. While these adaptations were justifiable there are several potential limitations that may explain the differences between the SST 

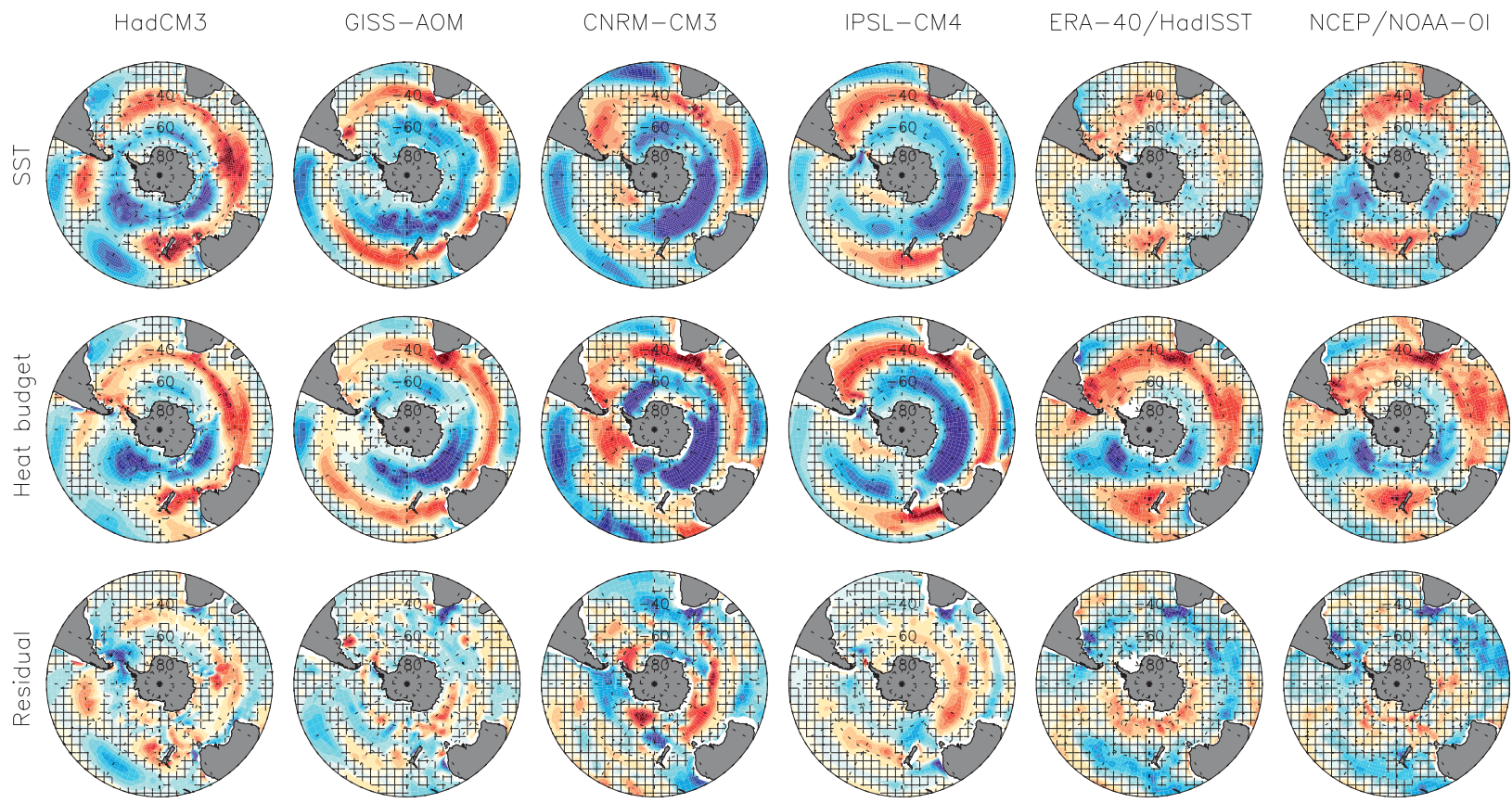

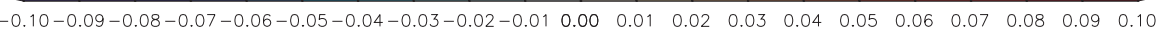

FIG. 5. Regression of (top) monthly mean sea surface temperature tendency $\left({ }^{\circ} \mathrm{C} 2 \mathrm{month}^{-1}\right)$, (middle) mixed layer temperature tendency from the heat budget, and (bottom) the residual (i.e., the component not captured by the heat budget) on the SAM index in (from left to right) HadCM3, GISS-AOM, CNRM-CM3, IPSL CM4, ERA-40/HadISST, and NCEP-NCAR/NOAA OI. The cross-hatching indicates regressions below the $95 \%$ significance level.

tendency response and the heat budget. First, several terms from the full heat budget [Eq. (2)] were neglected. The non-Ekman (geostrophic) component of the horizontal advection terms, the vertical heat advection term, and the mixing terms have not been accounted for. Second, shallow stratification can occur in regions of strong air-sea exchange, leading to differences between the mixed layer temperature and SST. Thus, the mixed layer temperature and the SST may not be fully interchangeable (Grodsky et al. 2008) and the mixed layer temperature tendency may not be fully representative of changes in SST. Furthermore, the mixed layer temperature tendency is sensitive to assumptions about the depth of penetration of the wind-driven flow. Here the assumption was made that the Ekman layer is shallower than the mixed layer. This is generally thought to be valid, although in certain locations Ekman transport penetrates below the mixed layer (Chereskin and Roemmich 1991; Chereskin and Price 2001). If the Ekman transport penetrates below the mixed layer, then the mixed layer temperature change will be less than that estimated assuming all of the heat transport is within the mixed layer. Third, in the cases of ERA-40/HadISST and NCEP-NCAR/NOAA OI, the evaluation may suffer from uncertainties in the reanalyses and SST data- sets. Reassuringly, the heat budget responses are highly similar in the two reanalyses (Fig. 5, middle row). The SST tendency responses in HadISST and NOAA OI (Fig. 5, top row) have very similar spatial patterns, but in HadISST the magnitude of the response is reduced (as discussed earlier). Thus, the residual component is somewhat sensitive to the choice of reference SST dataset (Fig. 5, bottom row). It is worth noting that the reanalyses' residual components are not noticeably larger than those in the models. Because the models are unaffected by observational errors, this implies that the residuals mainly come from approximations made in the heat budget and not from errors in the observations.

\section{Model errors}

To a good approximation, our simplified heat budget successfully explains the SST response to the SAM in both the simulations and observations. In part, the motivation for the heat budget analysis was to better understand the discrepancies between the simulated and observed SST responses to the SAM. We now consider these model errors in more detail. In Fig. 6 (top row) the NOAA OI SST tendency response is subtracted from the simulated responses. Thus, positive errors correspond 

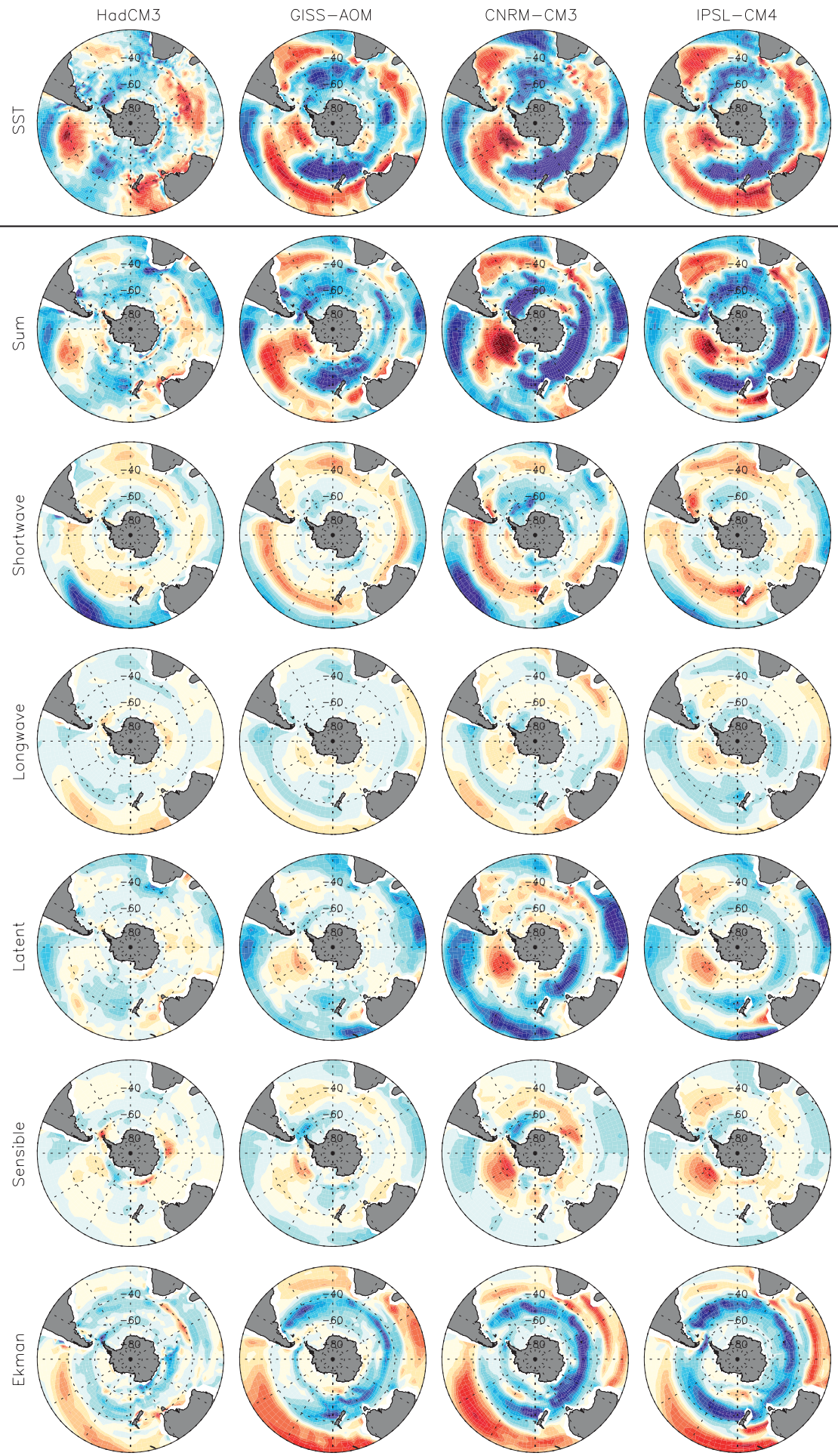

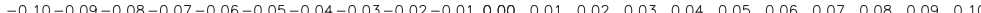

FIG. 6. Simulated errors in the (top)-(bottom) sea surface temperature tendency response to the SAM, mixed layer temperature tendency response from the heat budget, and responses of the component terms of the mixed layer heat budget in (from left to right) HadCM3, GISS-AOM, CNRM-CM3, and IPSL CM4. All plots represent the simulated regression map minus the observed regression map $\left({ }^{\circ} \mathrm{C} 2\right.$ month $\left.^{-1}\right)$. 
to regions where the simulation warms too much in response to a positive anomaly in the SAM index and negative errors to regions where the simulation cools too much. Below, in Fig. 6 (second row), are the errors derived from the heat budget (i.e., the simulated minus NCEP-NCAR/NOAA OI mixed layer temperature tendencies). The simulated SST errors are well captured by the heat budget.

Although the models have their own specific errors, the patterns of model error show two features common to all the simulations. First, all of the simulations show warming errors in the central Pacific sector (Fig. 6, top row). Second, they all show exaggerated cooling in the latitudes of $40^{\circ}-65^{\circ} \mathrm{S}$ (excluding the central Pacific). Karpechko et al. (2009) show similar deficiencies in the CMIP3 multimodel mean SST response. This suggests that the problems we have identified in this subset of models may be common among the CMIP3 coupled climate models. The magnitudes of the errors are considerable, that is, of equal magnitude to the SST response itself (Fig. 1, bottom row), in all of the models examined. A similar pattern of errors are found using ERA-40/ HadISST as the reference datasets, although the errors are slightly larger because of the weaker SST tendency response in HadISST relative to the NOAA OI.

The errors in the simulated mixed layer heat budget have been split into the constituent terms (Fig. 6, third to bottom rows). The largest errors are found in the $F_{\mathrm{EK}}$ term. All of the models show excessive cooling in the latitudes of $40^{\circ}-65^{\circ} \mathrm{S}$ and warming between $20^{\circ}$ and $40^{\circ} \mathrm{S}$ resulting from the $F_{\mathrm{EK}}$ term. Ultimately, this arises due to a stronger wind response in the models (Fig. 4). The errors in $F_{\mathrm{EK}}$ are primarily responsible for the exaggerated cooling in the $40^{\circ}-65^{\circ} \mathrm{S}$ latitude band (excluding the central Pacific sector).

The simulated warming errors in the central Pacific sector arise primarily due to problems in the $Q_{L}$ and $Q_{S}$ responses (Fig. 6, fifth and sixth rows). Recalling earlier discussions, the simulations show too weakly negative or positive responses in the turbulent heat fluxes $\left(Q_{L}\right.$ and $\left.Q_{S}\right)$ in this region. Thus, the simulations warm more. The differences in the turbulent heat fluxes may arise due to the greater asymmetry of the SAM in the central Pacific in the reanalyses compared to the simulations (Fig. 1, top row).

North of $40^{\circ} \mathrm{S}$, the errors in the simulated heat budget response predominantly result from a combination of the $Q_{\mathrm{SW}}, Q_{L}$, and $F_{\mathrm{EK}}$ terms (Fig. 6). Three out of four models (GISS-AOM, CNRM-CM3, and IPSL CM4) show excessive warming centered at $35^{\circ}-40^{\circ} \mathrm{S}$ resulting from overly strong increases in $Q_{\mathrm{Sw}}$ (Fig. 6, third row). In turn, the errors in the $Q_{\mathrm{sw}}$ responses stem from larger decreases in cloud cover in the models compared to the reanalyses (Table 2). The $Q_{L}$ errors north of $40^{\circ} \mathrm{S}$ are predominantly cooling (Fig. 6, fourth row) and result from simulated decreases in $Q_{L}$ that do not appear in the reanalyses (Fig. 3, third row). CNRM-CM3 shows particularly large errors in the $Q_{L}$ term, which dominates the heat budget errors north of $40^{\circ} \mathrm{S}$. The $F_{\mathrm{EK}}$ term shows excessive warming in the latitudes of $20^{\circ}-40^{\circ} \mathrm{S}$ (Fig. 6, bottom row); however, in many regions, it is offset by errors of the opposite sign in the other terms (predominantly $Q_{L}$ ).

\section{Summary and conclusions}

We have examined the mixed layer temperature response to the SAM using a simplified heat budget, including the effects of air-sea heat fluxes and Ekman heat transport, but neglecting the effects of geostrophic heat advection, vertical heat advection, and mixing. The simplified heat budget successfully reproduces both the spatial patterns and magnitudes of the simulated and observed SST responses to the SAM. Thus, at least on monthly time scales, the effects of geostrophic and vertical heat advection and mixing are small. On longer time scales, advection of SST anomalies by the Antarctic Circumpolar Current (ACC) may become increasingly important (Verdy et al. 2006; Maze et al. 2006). The observed SST response is dominated by changes in the turbulent $\left(Q_{S}\right.$ and $\left.Q_{L}\right)$ heat fluxes and Ekman $\left(F_{\mathrm{EK}}\right)$ heat transport, in agreement with previous studies (Verdy et al. 2006; Ciasto and Thompson 2008). The radiative heat fluxes $\left(Q_{\mathrm{SW}}\right.$ and $\left.Q_{\mathrm{LW}}\right)$ play a lesser but nonnegligible role. The models overestimate the wind response to the SAM, which leads to exaggerated cooling (during positive SAM) by Ekman transport in the latitudes of $40^{\circ}-65^{\circ} \mathrm{S}$, with the notable exception of the central Pacific sector $\left(90^{\circ}-150^{\circ} \mathrm{W}\right)$, where other errors dominate. Russell et al. (2006) show that the mean position and strength of the circumpolar westerlies varies considerably between the CMIP3 models. We have further shown substantial differences in the strength of the wind response to the SAM. In our subset, all of the models show a larger wind response than the reanalyses. Karpechko et al. (2009) find that only one of the CMIP3 models has a wind response weaker than ERA-40, and most models exaggerate the response. In addition, the wind stress response appears sensitive to the formulation of the drag coefficients in the models. Future changes in the winds (closely related to the SAM trend) are key to the projected changes in the Southern Ocean and a major component of intermodel variability results from surface wind differences in the CMIP3 models (Sen Gupta et al. 2009).

The reanalyses's SLP responses to the SAM exhibit zonal asymmetry in the central Pacific sector, which is 
less pronounced in the simulations. This error propagates to other atmospheric fields including the turbulent heat fluxes. The reanalyses show decreases in $Q_{S}$ and $Q_{L}$ in response to a positive anomaly in the SAM index that are poorly represented in the simulations (arguably with the exception of HadCM3). As a consequence, the simulated SST responses are too warm in the central Pacific sector. The negative $Q_{S}$ response in this region may result from negative SAT anomalies. In turn, the cold SAT may be due to enhanced advection of relatively cold air associated with the zonal asymmetry in the SLP response, which is poorly simulated by the models.

Substantial errors are also found in the simulated $Q_{\text {sw }}$ responses owing to problems in the representation of cloud. The models have an overly strong and unrealistic spatial pattern of cloud cover response to the SAM.

The analyses have highlighted the sources of error in the simulated monthly SST responses to the SAM in four of the CMIP3 models. Because similar errors are found in the CMIP3 multimodel mean (Karpechko et al. 2009), it is likely that the deficiencies identified are common to other climate models. Additional errors are expected on longer time scales because of the inability of these models to explicitly resolve mesoscale eddies. The longterm SST response to the SAM is likely to be influenced by changes in heat transport resulting from slow modifications of the mesoscale eddy field (Screen et al. 2009).

Acknowledgments. The manuscript has benefited from useful discussions with Gareth Marshall and Howard Roscoe, and insightful comments from three anonymous reviewers. JAS and NPG acknowledge financial support from the Leverhulme Trust NPG and AYK were supported by NERC Grant NE/E006787/1. We thank the research programs and modeling groups that contributed to the WCRP CMIP3 multimodel dataset. ECMWF is acknowledged for providing ERA-40 data. NCEPNCAR reanalysis and NOAA OI data were obtained through the NOAA/Earth System Research Laboratory. HadISST data were obtained from the British Atmospheric Data Centre. Clément de Boyer Montégut and colleagues are thanked for compiling and making available the observed mixed layer depth climatology.

\section{REFERENCES}

Arblaster, J., and G. Meehl, 2005: Contributions of external forcings to southern annular mode trends. J. Climate, 19, 2896-2905.

Bengtsson, L., S. Hagemann, and K. I. Hodges, 2004: Can climate trends be calculated from reanalysis data? J. Geophys. Res., 109, D11111, doi:10.1029/2004JD004536.

Blanke, B., and P. Delecluse, 1993: Variability of the tropical Atlantic Ocean simulated by a general circulation model with two different mixed-layer physics. J. Phys. Oceanogr., 23, 1363-1388.
Bretherton, C., M. Widmann, V. Dymnikov, J. Wallace, and I. Blade, 1999: The effective number of spatial degrees of freedom of a time-varying field. J. Climate, 12, 1900-2009.

Bromwich, D., and R. Fogt, 2004: Strong trends in the skill of the ERA-40 and NCEP-NCAR reanalyses in the high and middle latitudes of the Southern Hemisphere, 1958-2001. J. Climate, 17, 4603-4619.

Butler, A. H., D. W. J. Thompson, and K. R. Gurney, 2007: Observed relationships between the Southern Annular Mode and atmospheric carbon dioxide. Global Biogeochem. Cycles, 21, GB4014, doi:10.1029/2006GB002796.

Cai, W., and I. Watterson, 2002: Modes of interannual variability of the Southern Hemisphere circulation simulated by the CSIRO climate model. J. Climate, 15, 1159-1174.

- and T. Cowan, 2007: Trends in Southern Hemisphere circulation in IPCC AR4 models over 1950-99: Ozone depletion versus greenhouse forcing. J. Climate, 20, 681-693.

Chereskin, T., 1995: Direct evidence for an Ekman balance in the California Current. J. Geophys. Res., 100, 18 261-18 269.

- and D. Roemmich, 1991: A comparison of measured and wind-derived Ekman transport at $11^{\circ} \mathrm{N}$ in the Atlantic Ocean. J. Phys. Oceanogr., 21, 869-878.

pedia of Ocean Sciences, Academic Press, 809-815.

Ciasto, L., and D. Thompson, 2008: Observations of large-scale ocean-atmosphere interaction in the Southern Hemisphere. J. Climate, 21, 1244-1259.

Connolley, W. M., and T. J. Bracegirdle, 2007: An Antarctic assessment of IPCC AR4 coupled models. Geophys. Res. Lett., 34, L22505, doi:10.1029/2007GL031648.

de Boyer Montégut, C., G. Madec, A. S. Fischer, A. Lazar, and D. Iudicone, 2004: Mixed layer depth over the global ocean: An examination of profile data and a profile-based climatology. J. Geophys. Res., 109, C12003, doi:10.1029/2004JC002378.

Ekman, V., 1905: On the influence of the earth's rotation on ocean currents. Ark. Mat. Astron. Fys., 2, 1-53.

Eyring, V., and Coauthors, 2007: Multimodel projections of stratospheric ozone in the 21st century. J. Geophys. Res., 112, D16303, doi:10.1029/2006JD008332.

Fairall, C., E. Bradley, J. Hare, A. Grachev, and J. Edson, 2003: Bulk parameterization of air-sea fluxes: Updates and verification for the COARE algorithm. J. Climate, 16, 571-591.

Gillett, N., and D. Thompson, 2003: Simulation of recent Southern Hemisphere climate change. Science, 302, 273-275.

, T. D. Kell, and P. D. Jones, 2006: Regional climate impacts of the Southern Annular Mode. Geophys. Res. Lett., 33, L23704, doi:10.1029/2006GL027721.

Grodsky, S. A., J. A. Carton, and H. Liu, 2008: Comparison of bulk sea surface and mixed layer temperatures. J. Geophys. Res., 113, C10026, doi:10.1029/2008JC004871.

Hall, A., and M. Visbeck, 2002: Synchronous variability in the Southern Hemisphere atmosphere, sea ice, and ocean resulting from the annular mode. J. Climate, 15, 3043-3057.

Josey, S. A., E. C. Kent, and P. K. Taylor, 2002: Wind stress forcing of the ocean in the SOC climatology: Comparisons with NCEP-NCAR, ECMWF, UWM/COADS, and Hellerman and Rosenstein datasets. J. Phys. Oceanogr., 32, 19932019.

Kalnay, E., and Coauthors, 1996: The NCEP-NCAR 40-Year Reanalysis Project. Bull. Amer. Meteor. Soc., 77, 437-471.

Karpechko, A., N. Gillett, G. Marshall, and J. Screen, 2009: Climate impacts of the southern annular mode simulated by the CMIP3 models. J. Climate, 22, 3751-3768. 
Kraus, E., and J. Turner, 1967: A one-dimensional model of the seasonal thermocline: II. The general theory and its consequences. Tellus, 19, 98-106.

Large, W., J. McWilliams, and S. Doney, 1994: Oceanic vertical mixing: A review and a model with a non-local boundary layer parameterization. Rev. Geophys., 32, 363-403.

Lefebvre, W., H. Goosse, R. Timmermann, and T. Fichefet, 2004: Influence of the Southern Annular Mode on the sea iceocean system. J. Geophys. Res., 109, C09005, doi:10.1029/ 2004JC002403.

Lovenduski, N. S., and N. Gruber, 2005: Impact of the Southern Annular Mode on Southern Ocean circulation and biology. Geophys. Res. Lett., 32, L11603, doi:10.1029/2005GL022727.

, - S. C. Doney, and I. D. Lima, 2007: Enhanced $\mathrm{CO}_{2}$ outgassing in the Southern Ocean from a positive phase of the Southern Annular Mode. Global Biogeochem. Cycles, 21, GB2026, doi:10.1029/2006GB002900.

Marshall, G., 2003: Trends in the southern annular mode from observations and reanalyses. J. Climate, 16, 4134-4143.

—_ 2007: Half-century seasonal relationships between the Southern Annular Mode and Antarctic temperatures. Int. J. Climatol., 27, 373-383.

—, P. A. Stott, J. Turner, W. M. Connolley, J. C. King, and T. A. Lachlan-Cope, 2004: Causes of exceptional atmospheric circulation changes in the Southern Hemisphere. Geophys. Res. Lett., 31, L14205, doi:10.1029/2004GL019952.

Maze, G., F. D'Andrea, and A. C. de Verdiere, 2006: Low-frequency variability in the Southern Ocean region in a simplified coupled model. J. Geophys. Res., 111, C05010, doi:10.1029/ 2005JC003181.

Meehl, G., C. Covey, T. Delworth, M. Latif, B. McAvaney, J. Mitchell, R. Stouffer, and K. Taylor, 2007: The WCPP CMIP3 multimodel dataset: A new era in climate change research. Bull. Amer. Meteor. Soc., 88, 1383-1394.

Miller, R. L., G. A. Schmidt, and D. T. Shindell, 2006: Forced annular variations in the 20th century Intergovernmental Panel on Climate Change Fourth Assessment Report models. J. Geophys. Res., 111, D18101, doi:10.1029/2005JD006323.

Perlwitz, J., S. Pawson, R. L. Fogt, J. E. Nielsen, and W. D. Neff, 2008: Impact of stratospheric ozone hole recovery on Antarctic climate. Geophys. Res. Lett., 35, L08714, doi:10.1029/ 2008GL033317.

Raphael, M., and M. Holland, 2006: Twentieth century simulation of the Southern Hemisphere climate in coupled models. Part 1: Large-scale circulation variability. Climate Dyn., 26, 217-228.

Rayner, N. A., D. E. Parker, E. B. Horton, C. K. Folland, L. V. Alexander, D. P. Rowell, E. C. Kent, and A. Kaplin, 2003: Global analyses of sea surface temperature, sea ice, and night marine air temperature since the late nineteenth century. J. Geophys. Res., 108, 4407, doi:10.1029/2002JD002670.

Reichler, T., and J. Kim, 2008: Uncertainties in the climate mean state of global observations, reanalyses, and the GFDL climate model. J. Geophys. Res., 113, D05106, doi:10.1029/ 2007JD009278.
Reynolds, R., N. Rayner, T. Smith, D. Stokes, and W. Wang, 2002: An improved in situ and satellite SST analysis for climate. J. Climate, 15, 1609-1625.

Rossow, W., and R. Schiffer, 1999: Advances in understanding clouds from ISCCP. Bull. Amer. Meteor. Soc., 80, 2261-2288.

Russell, J., R. Stouffer, and K. Dixon, 2006: Intercomparison of the Southern Ocean circulations in IPCC coupled model control simulations. J. Climate, 19, 4560-4575.

Schudlich, R., and J. Price, 1998: Observations of seasonal variation in the Ekman layer. J. Phys. Oceanogr., 28, 1187-1204.

Screen, J., N. Gillett, D. Stevens, G. Marshall, and H. Roscoe, 2009: The role of eddies in the Southern Ocean temperature response to the Southern Annular Mode. J. Climate, 22, 806-818.

Sen Gupta, A., and M. England, 2006: Coupled ocean-atmosphereice response to variations in the southern annular mode. J. Climate, 19, 4457-4486.

— and - 2007: Coupled ocean-atmosphere feedback in the southern annular mode. J. Climate, 20, 3677-3692.

- A. Santoso, A. Taschetto, C. Ummenhofer, M. England, and J. Trevena, 2009: Projected changes to the Southern Hemisphere ocean and sea ice in the IPCC AR4 climate models. J. Climate, 22, 3047-3078.

Shindell, D. T., and G. A. Schmidt, 2004: Southern Hemisphere climate response to ozone changes and greenhouse gas increases. Geophys. Res. Lett., 31, L18209, doi:10.1029/ 2004GL020724.

Solomon, S., D. Qin, M. Marquis, K. Averyt, M. Tignor, and H. L. Miller, Eds., 2007: Climate Change 2007: The Physical Science Basis. Cambridge University Press, 996 pp.

Son, S.-W., and Coauthors, 2008: The impact of stratospheric ozone recovery on the Southern Hemisphere westerly jet. Science, 320, 1486-1489.

Stammerjohn, S. E., D. G. Martinson, R. C. Smith, X. Yuan, and D. Rind, 2008: Trends in Antarctic annual sea ice retreat and advance in relation to El Niño-Southern Oscillation and Southern Annular Mode variability. J. Geophys. Res., 113, C03S90, doi:10.1029/2007JC004269.

Sterl, A., 2004: On the (in)homogeneity of reanalysis products. J. Climate, 17, 3866-3873.

Thompson, D., and J. Wallace, 2000: Annular modes in the extratropical circulation. Part I: Month-to-month variability. J. Climate, 13, 1000-1016. , and S. Solomon, 2002: Interpretation of recent Southern Hemisphere climate change. Science, 296, 895-899.

_ J. Wallace, and G. Hegerl, 2000: Annular modes in the extratropical circulation. Part II: Trends. J. Climate, 13,1018-1036.

Uppala, S., and Coauthors, 2005: The ERA-40 Re-Analysis. Quart. J. Roy. Meteor. Soc., 131, 2961-3012.

Verdy, A., J. Marshall, and A. Czaja, 2006: Sea surface temperature variability along the path of the Antarctic Circumpolar Current. J. Phys. Oceanogr., 36, 1317-1331.

Watterson, I., 2001: Zonal wind vacillation and its interaction with the ocean: Implications for interannual variability and predictability. J. Geophys. Res., 106, 23 965-23975. 